\title{
Assessment and Practice of Civil Engineering Survey Based on PDCA Mode
}

\author{
Jiansheng Shen, Huiyan Jia ${ }^{1 *}$, Wenhao Zhang and Jian Gen \\ ${ }^{1}$ School of Civil Engineering and Architecture, Ningbo Tech University, 1 Qianhu road, Ningbo 315100,China \\ Email: sjs@nit.zju.edu.cn \\ *Corresponding author.Email:_huiyanj@nit.ziu.edu.cn
}

\begin{abstract}
In view of the teaching problems existing in the civil engineering surveying course, the design of evaluation methods and practical exploration were carried on the teaching methods, of civil engineering surveying based on the PDCA cycle mode. The teaching links of the course theory teaching, experiment and practice were fit together. Self-innovative learning, experimental design, practical operating, and result analysis of students were train. The result shows that the teaching method based on PDCA mode improves and cultivates students' engineering practice ability and engineering innovation ability.
\end{abstract}

Keywords: Evaluation methods, Practical exploration, PDCA mode.

\section{INTRODUCTION}

Civil engineering survey, as a general course of civil engineering undergraduate major, is a professional basic course that must be mastered by students with strong application[1]. It mainly studies the measurement problems in the field of construction engineering, and its task is to enable students to acquire and master the basic knowledge and measurement operation skills of engineering measurement through various teaching links of theory and practice, and to complete the measurement and measurement analysis of engineering according to the needs of actual engineering design, construction, operation and maintenance. Therefore, it is of great significance to explore and construct the course scientifically and reasonably in terms of teaching content, teaching methods, teaching means, practice links and assessment methods, so as to improve the teaching effect and quality[2].

In recent years, with the vigorous development of civil engineering majors in my country, the number of professional enrollment has increased sharply, which has made the shortage of engineering survey teaching, equipment, teachers and venues increasingly serious[3,4]. Quite a number of students have low practical ability, do not understand the field measurement method, cannot use advanced instruments, cannot flexibly use measurement knowledge to solve practical problems and other phenomena[5,6]. In addition, after the implementation of the new syllabus, the classroom teaching and experimental hours are reduced, which brings new challenges to the quality and effectiveness of engineering measurement teaching[1,2]. How to improve the teaching quality and effect of civil engineering survey course under the requirements of the new syllabus is an urgent problem to be solved.

Based on PDCA cycle mode, this paper designs the assessment mode of civil engineering survey course and explores the practice of teaching mode, and integrates active innovative learning into all aspects of civil engineering survey course teaching.

\section{EXISTING PROBLEMS IN TEACHING}

At present, there are mainly the following problems in the teaching of civil engineering surveying courses: 


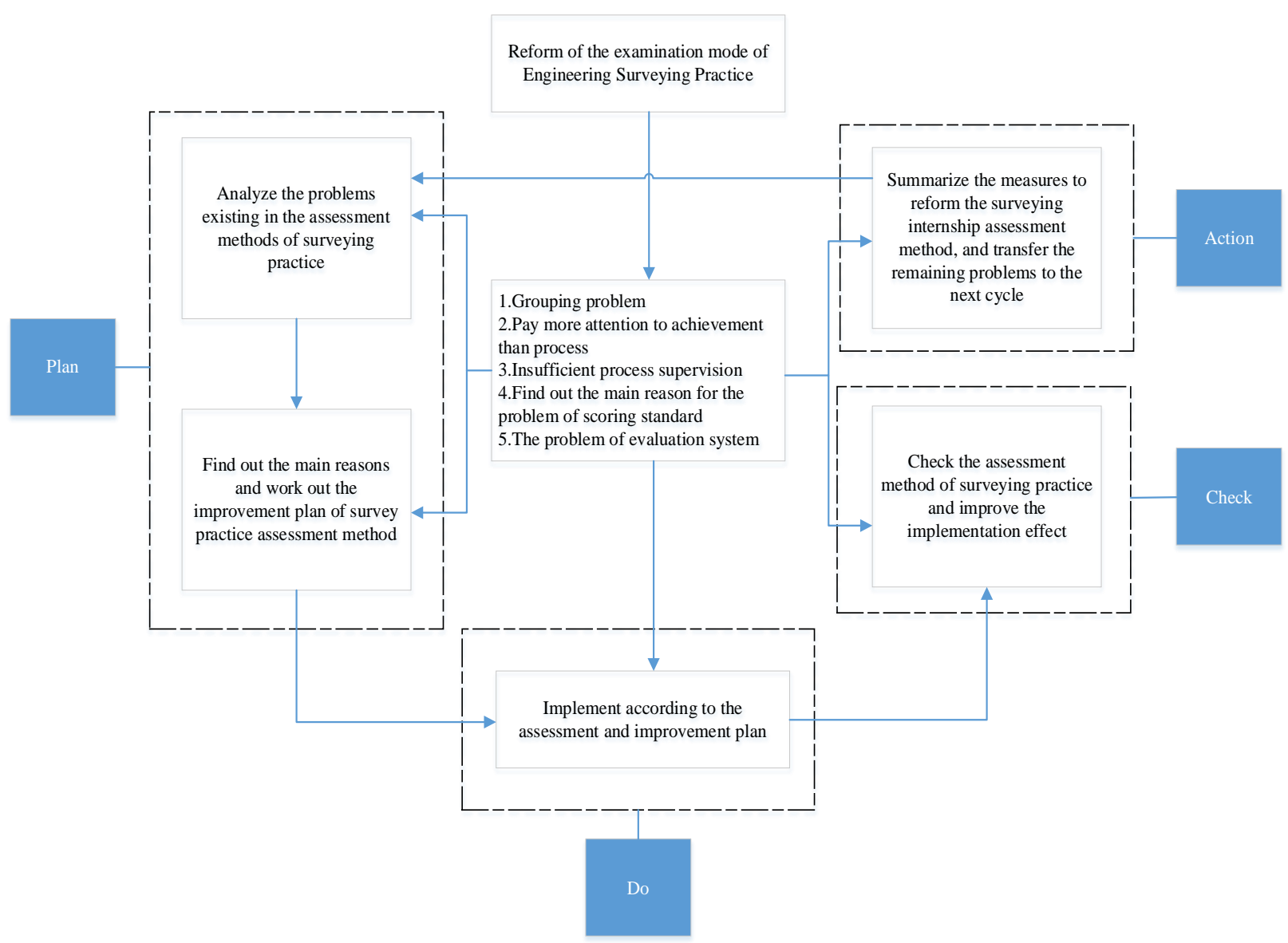

Figure 1 Design roadmap of teaching practice assessment method based on PDCA cycle

(1)The whole measurement experiment practice is carried out step by step according to the requirements of the instructor's task book and process guidance. Students are lack of independent thinking, low level of understanding and low ability of hands-on operation.

(2)Some students have insufficient enthusiasm and initiative to deal with measurement experiments and internships, fail to truly complete measurement experiment internships independently, and instruct teachers have limited supervision methods.

(3)The evaluation of measurement practice results is based on the final results handed in by students, which may cover up the efforts of students in the measurement experiment practice and the degree of independent completion, resulting in the result evaluation is not objective, especially the fairness of measurement practice group and the level of group members will directly affect the group's results.

\section{DESIGN OF TEACHING PRACTICE ASSESSMENT MODE BASED ON PDCA}

According to the present problems of surveying internship achievement evaluation, design building engineering surveying internship achievement assessment evaluation index, from the field measurement, calculation, discipline and attendance in the industry, to examine the internship report four parts, emphasis on practice stage in the process of examination, to increase the operation skills evaluation weights, students can develop a objective evaluation of engineering surveying exercitation effect evaluation system.

The design roadmap of teaching practice assessment method based on PDCA cycle is shown in Fig.1. The evaluation of internship and practice results is composed of five parts: field measurement, field calculation, discipline and attendance, internship report and practice report. The evaluation system is formulated, focusing on the evaluation of operation skills, and the problems existing in the evaluation method of engineering survey practice are continuously improved.

\section{TEACHING PRACTICE OF ENGINEERING SURVEY BASED ON PDCA}

Based on the PDCA cycle mode teaching method of engineering survey teaching design, the new teaching method, PDCA cycle mode teaching method, is implemented for class 3 and class 4 of Civil Engineering Specialty in our university in 2013. Class 1 and class 2 of 2013 are compared, that is, according to the previous teaching methods. 
Table 1. Active learning method

\begin{tabular}{|c|c|}
\hline Learning purpose & $\begin{array}{l}\text { This course aims to cultivate the ability of searching (analysis, comparison, selection), } \\
\text { sorting, analysis, and expressing opinions }\end{array}$ \\
\hline Form of expression & $\begin{array}{l}\text { In general, a group of } 5 \text { people, each class learning content, collect information, send } \\
\text { representatives to report on stage (PPT form), demonstration (instrument operation); } \\
\text { directly count into the final exam score of } 15 \text { points. }\end{array}$ \\
\hline Time allocation & 5 class hours (4 groups / class hour, about 20 groups in total) \\
\hline \multirow{6}{*}{ Assessment criteria } & $\begin{array}{l}\text { Each group should avoid repeating the content completely, otherwise it will be punished } \\
\text { as plagiarism, and } 0 \text { point will be recorded; }\end{array}$ \\
\hline & $\begin{array}{l}\text { The time should be controlled at } 10-5 \text { minutes, and the overtime or less time should be } \\
\text { regarded as the deduction condition; }\end{array}$ \\
\hline & $\begin{array}{l}\text { At the end of the report, the teacher and students can ask questions. The teacher and } \\
\text { members of each group will give their own scores (1-10 points) according to the } \\
\text { situation of reporting and answering questions, and take the average after removing the } \\
\text { highest and lowest scores; }\end{array}$ \\
\hline & $\begin{array}{l}\text { Teachers and members of each group should not have full marks, otherwise it will be } \\
\text { invalid; }\end{array}$ \\
\hline & $\begin{array}{l}\text { Students who report on the stage will be given } 2 \text { points on the basis of the average } \\
\text { score, not more than } 10 \text { points; }\end{array}$ \\
\hline & $\begin{array}{l}\text { Each study group will summarize the materials of each report, print and submit them in } \\
\text { the form of report (including ppt of report, print } 6 \text { sheets / page). Each group will design } \\
\text { the cover independently, and score according to the quality of materials, accounting for } \\
5 \text { points. }\end{array}$ \\
\hline
\end{tabular}

Before classes begin, according to the contents of the course learn each topic, will be applied to the equipment in the course of operation instructions, video and specification and other related information to students, cultivate the students' active learning, specific methods are shown in table 1 , the class 3 class 4 students into groups (mainly independent portfolio), by five people as a learning team, each time will be next time in class learning content theme layout in advance, to prepare the study group students after class, students can borrow the measuring instrument to the laboratory, autonomous learning to use ahead of time, the next class randomly selected one of the four groups. Delegates from each group will make presentations (or demonstration of measuring instruments, such as total station operation). At the end of the report, the teacher and the students can ask questions. The teacher and each group member will give a score (1-10 points) according to the report and answer questions. The report group will conduct self-evaluation at the same time and get an average score after excluding the highest and lowest scores. Each study group will summarize the materials for each report into the form of printing and handing them in, and score them according to the quality of the materials (accounting for 5 points).

Each group leader will give four grades of a, B, C and $\mathrm{d}$ according to the performance of the team members in terms of the number of tasks, completion and contribution of each learning topic. The teacher will score them in combination with the quality of the learning topic materials submitted, which will be included in the autonomous learning performance.

At the end of the course, comprehensive assessment is carried out from four aspects, including final examination score accounting for $50 \%$, measurement experiment score accounting for $20 \%$, daily work attendance score accounting for $15 \%$, autonomous learning score accounting for $15 \%$, and the final evaluation score is given.

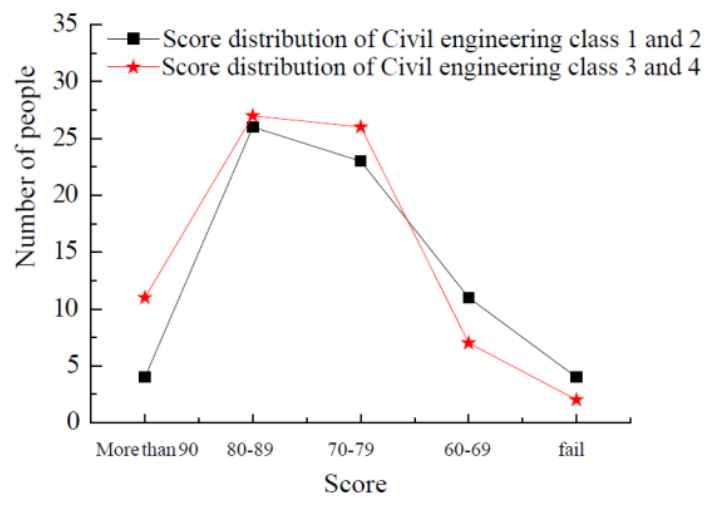

Figure 2 Comparison of the distribution of the total course evaluation results

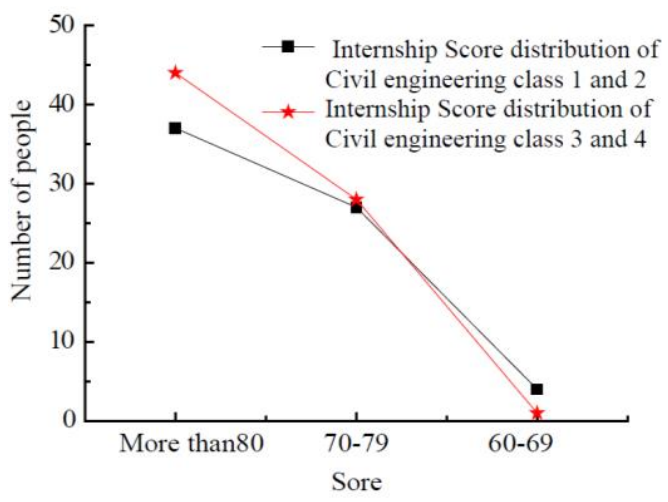

Figure 3 Comparison of the distribution of the course internship results 
Based on the PDCA teaching design of engineering survey, four classes of 2013 civil engineering major in our school have carried out the exploration of engineering survey theory teaching and practice according to the above methods. Fig. 2 and Fig. 3 show the distribution comparison chart of the total course evaluation results and the distribution comparison chart of the course practice results of the four classes. It can be seen from the figure that the results of class 3 and class 4 using the above method are significantly better than those of class 1 and class 2. Among them, the number of students with a total score of more than 90 points in class 3 and class 4 is about three times that of class 1 and class 2 . In the process of surveying internship, the ability of independent experiment design, practical operation and experimental result analysis of class 3 and class 4 are obviously better than Class 1 and class 2 , which shows that the above teaching methods have better effect and help to improve and cultivate students' engineering practice ability and engineering innovation ability.

Although the above teaching methods are effective, how to test students' ability to solve survey problems in practical engineering needs further consideration. For example, holding engineering survey competition activities, these problems can be transferred to the next PDCA cycle for improvement.

\section{CONCLUSION}

Based on the teaching method of PDCA cycle mode, the design of evaluation methods and practical exploration were carried on the teaching methods, Combining the teaching links of theory teaching, experiment and practice, it is proposed that active and innovative learning should be integrated into the teaching of civil engineering surveying. To improve students' initiative and innovation ability in theoretical learning and practice, and to cultivate students' ability of autonomous learning, experimental design, practical operation and calculation result analysis.

\section{AUTHORS' CONTRIBUTIONS}

The background research for this publication was carried out by all authors. Jiansheng Shen wrote this manuscript, and Wenhao Zhang translated the manuscript. Huiyan Jia reviewed this manuscript.

\section{ACKNOWLEDGMENTS}

The authors wish to acknowledge the financial support of the Ningbo Tech University (NITJG-201919), Zhejiang Provincial Laboratory Work Research Project(YB202132) and the cooperative education project of Zhejiang provincial (Reform and innovation of civil construction curriculum system based on "intelligent construction" under the background of new engineering).

\section{REFERENCES}

[1] Yu Jiayong, On the teaching reform of civil engineering surveying course $[\mathrm{J}]$. Engineering of Surveying and Mapping, 2014,vol.01, pp.78-80. DOI:10.3969/j.issn.1006-7949.2014.01.018.

[2] Wang Anyi, Chen Changping, SHEN Lu. Research and Construction of the Practical Teaching System for Engineering Survey Course[J].Geomatics \& Spatial Information Technolagy, 2014,vol.01, pp.76-78.

DOI:10.3969/j.issn.1672-5867.2014.01.022.

[3] Xiao Taoming, Ai Ming.Discussion on practical teaching reform of civil engineering survey[J]. Journal of Yangtze University,2014,vol.11,pp.115-116.DOI:10.16772/j. cnki.1673-1409.2014.25.021.

[4] Li Qiao. Practice and Thinking on teaching reform of engineering survey course[J].Industrial \& Science Tribune, 2014,vol.13,pp.155-156. DOI:10.3969/j.issn.1673-5641.2014.13.086.

[5] Dong Hongjing. Design and construction of the surveying internships performance evaluation system[J], Geology and Mineral Surveying, 2012, vol.28,pp.

43-45.

DOI:10.3969/j.issn.1007-9394.2012.04.015.

[6] He Yonghong. Discussion on the teaching reform of civil engineering surveying practice $[\mathrm{J}]$. Journal of Hunan University of Science and Technology, 2012, vol.33, pp.145-146.

DOI:10.3969/j.issn.1673-2219.2012.04.046. 